\title{
Determination of Picogram Levels of Roxithromycin in Pharmaceutical, Human Serum, and Urine by Flow-Injection Chemiluminescence
}

\author{
Jiangman Liu, Huan Yang, Yun Zhang, Min Wu, Haixiang Zhao, and Zhenghua Song \\ Key Laboratory of Synthetic and Natural Functional Molecule Chemistry of Ministry of Education, College of Chemistry \& Material \\ Science, Northwest University, Xi'an 710069, China \\ Correspondence should be addressed to Zhenghua Song, songzhenghua@hotmail.com
}

Received 20 August 2011; Accepted 25 September 2011

Academic Editors: V. Maier and A. Taga

Copyright () 2012 Jiangman Liu et al. This is an open access article distributed under the Creative Commons Attribution License, which permits unrestricted use, distribution, and reproduction in any medium, provided the original work is properly cited.

\begin{abstract}
A sensitive chemiluminescence (CL) method, based on the inhibitory effect of roxithromycin (ROX) on the CL reaction between luminol and dissolved oxygen in a flow-injection system, was first proposed for the determination of ROX at picogram levels. The decrement of CL intensity was linearly proportional to the logarithm of ROX concentrations ranging from 0.1 to $100 \mathrm{pg} \mathrm{mL}$, giving the limit of detection (LOD) of $0.03 \mathrm{pg} \mathrm{mL}^{-1}(3 \sigma)$. At a flow rate of $2.0 \mathrm{~mL} \mathrm{~min}^{-1}$, a complete analytical procedure including sampling and washing could be performed within $0.5 \mathrm{~min}$, with relative standard deviations (RSDs) of less than $5.0 \%(n=5)$. The proposed procedure was applied successfully to the determination of ROX in pharmaceutical, human serum, and urine with the recoveries ranging from 90.0 to $110.0 \%$.
\end{abstract}

\section{Introduction}

Roxithromycin (ROX, $\mathrm{C}_{41} \mathrm{H}_{76} \mathrm{~N}_{2} \mathrm{O}_{15}$ ) is a kind of antibiotic with semisynthetic 14-membered-ring macrolide antibiotic $[1-3]$ as shown in Figure 1. ROX has been frequently adopted as an effective treatment for several different infections, including respiratory tract infections asthma, gum infections like gingivitis, and bacterial infections associated with stomach as well as intestinal ulcers [4]. It works efficiently even at small doses with less frequent administration, which is regarded as a clinical advantage, and has a wide range of applications in human and veterinary medicines [5].

A variety of methods have been used for the determination of ROX (Table 1), including high-performance liquid chromatography (HPLC) [6-8], electrochemistry (EC) [9], fluorescence (FL) [10], aqueous two-phase system extraction (ATPSE) [11], capillary electrophoresis (CE) [12], and chemiluminescence (CL) [13]. Compared with other methods, CL has attracted increasing attention in various fields owing to its high sensitivity, wide linear dynamic range, rapid measurements, and simple instrumentation [14-17].

The simple and green CL system of luminol-dissolved oxygen has been applied for the determination of vitamin
$B_{12}$ [18], sudan IV [19] and chlorogenic acid [20] by our group. However, no CL method of luminol-dissolved oxygen system has been utilized for the determination of ROX to date. In this work, it was found that CL signal from luminol-dissolved oxygen reaction could be inhibited by ROX and the decrement of the CL intensity was linearly proportional to the logarithm of ROX concentrations ranging from 0.1 to $100 \mathrm{pg} \mathrm{mL}^{-1}$, with the linear equation of $\Delta I_{\mathrm{CL}}=6.73 \ln C_{\mathrm{ROX}}+23.62\left(R^{2}=0.9925, n=5\right)$ and the LOD of $0.03 \mathrm{pg} \mathrm{mL}^{-1}(3 \sigma)$. At a flow rate of $2.0 \mathrm{~mL} \mathrm{~min}^{-1}$, a complete analytical process could be performed within $0.5 \mathrm{~min}$, with relative standard deviations (RSDs) of less than $5.0 \%(n=5)$. The proposed procedure was applied successfully in the determination of ROX in pharmaceutical, human serum, and urine samples with the recoveries ranging from 90.0 to $110.0 \%$.

\section{Experimental}

2.1. Apparatus. A schematic diagram of the CL flowinjection system was shown in Figure 2. A peristaltic pump of the IFFL-DD luminescence analyzer (Xi' an Remax Electronic Science-Tech. Co. Ltd., Xi'an, China) was applied to deliver 
TABLE 1: Comparisons of different methods for determination of ROX.

\begin{tabular}{lccc}
\hline Methods & Linear range $(\mu \mathrm{g} \mathrm{mL}-1)$ & LOD $\left.(\mu \mathrm{g} \mathrm{mL})^{-1}\right)$ & References \\
\hline & $0.5-10.0$ & 0.2 & {$[6]$} \\
HPLC & $0.05-20.0$ & 0.05 & {$[7]$} \\
& $5.1-100.0$ & 5.1 & {$[8]$} \\
EC & $4.2-84$ & 0.4 & {$[9]$} \\
FL & $25.0-350.0$ & 4.6 & {$[10]$} \\
ATPSE & $1.0-20.0$ & 0.03 & {$[11]$} \\
CE & $0.02-201.0$ & $7.0 \times 10^{-3}$ & {$[12]$} \\
CL & $1.0 \times 10^{-6}-1.0 \times 10^{-3}$ & $3.0 \times 10^{-7}$ & {$[13]$} \\
Proposed method & $1.0 \times 10^{-7}-1.0 \times 10^{-4}$ & $3.0 \times 10^{-8}$ & This work \\
\hline
\end{tabular}

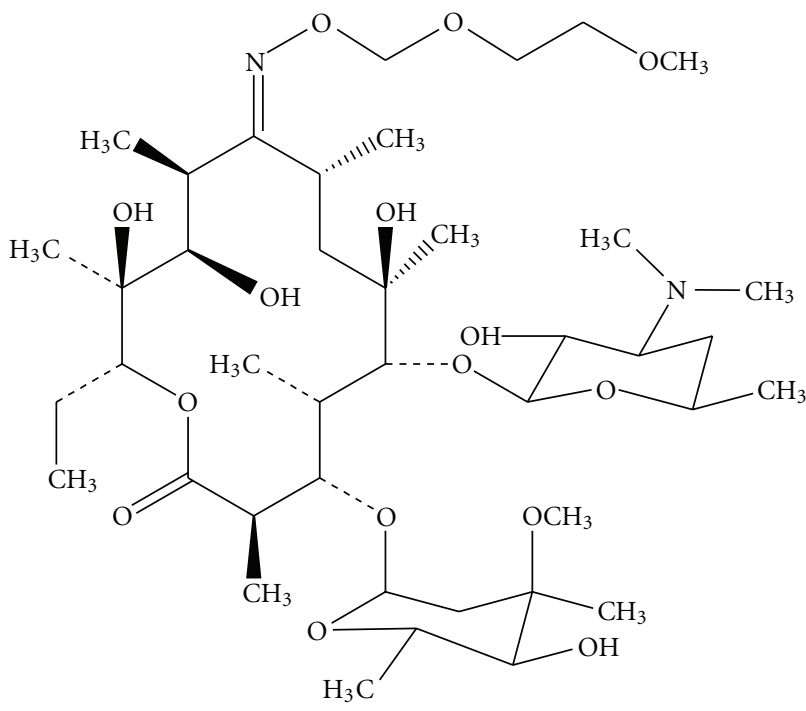

FIgURE 1: Schematic diagram of ROX structure.

all streams. PTFE tubing ( $1.0 \mathrm{~mm}$ i.d.) was used throughout the manifold for carrying the CL reagents. A six-way valve with a loop of $100.0 \mu \mathrm{L}$ was used for sampling. The CL signals produced in flow cell were detected without wavelength discrimination, and the photomultiplier tube (PMT) output was recorded by PC with the IFFL-DD client system.

2.2. Reagents. All the reagents were of analytical grade in this work. Water purified in a Milli-Q system (Millipore, Bedford, MA, USA) was used for the preparation of solutions in the whole procedure. Luminol (Fluka, Biochemika, Switzerland) was obtained from Xi'an Medicine Purchasing and Supply Station, Xi'an, China. The stock solution of luminol $\left(2.5 \times 10^{-2} \mathrm{~mol} \mathrm{~L}^{-1}\right)$ was prepared by dissolving $0.44 \mathrm{~g}$ luminol in $100 \mathrm{~mL}$ of $0.1 \mathrm{~mol} \mathrm{~L}^{-1} \mathrm{NaOH}$ solution in a brown calibrated flask. The stock solution ROX (Shaanxi Institute for Drug Control) of $1.0 \mathrm{mg} \mathrm{mL}^{-1}$ was stored at $4^{\circ} \mathrm{C}$. Working standard solutions were prepared daily from the above stock solution as required.

2.3. General Procedure. As shown in Figure $2,100 \mu \mathrm{L}$ luminol solution and the carrier (purified water) were injected into the flow system quantitatively via the six-way valve until a stable baseline was recorded. Then quantities of known concentration of ROX solutions were injected into the flow system and mixed with luminol reagent. The mixed solution in an alkaline medium was delivered into the CL flow cell, and CL signals were produced and measured by the PMT and luminometer. The concentration of the sample was quantified by the reduction of CL intensity $\left(\Delta I_{\mathrm{CL}}=I_{o}-I_{s}\right)$, where $I_{s}$ and $I_{o}$ were the CL intensity in the presence and absence of ROX, respectively.

\subsection{Sample Preparation}

2.4.1. Treatment of Pharmaceutical. ROX tablets (No. 6 Pharmaceutical Factory, Harbin, China) were purchased from local market. Five pieces of tablets (labelled amount $75 \mathrm{mg} \mathrm{tab}^{-1}$ ) were weighed up and ground to fine powder. Then the power of average one tablet was weighed out accurately, dissolved by water, and filtrated. The filter residue was washed several times, and then the solution was diluted to $250 \mathrm{~mL}$ calibrated flask. Suitable aliquots from this solution were taken for the determination of ROX, and the concentration of ROX was in the concentration range of its determination.

2.4.2. Treatment of Human Urine and Serum Sample. The urine sample was collected from healthy volunteers, and the serum sample was supplied by the Hospital of Northwest University. To prepare the spiked samples, known quantities of standard solution of ROX were spiked into $1.0 \mathrm{~mL}$ of urine or serum. After homogenization, the urine and the serum samples were diluted to proper multiples, respectively. Then the samples were determined by the proposed method directly after dilution.

\section{Results and Discussion}

3.1. CL Intensity-Time Profile. The relative CL intensity-time profile was shown in Figure 3. The luminol-dissolved oxygen CL reaction reached the maximum of CL intensity $\left(T_{\max }\right)$ at $7.0 \mathrm{~s}$ and then vanished within $26 \mathrm{~s}$; while in the presence of ROX $\left(5 \mathrm{pg} \mathrm{mL}^{-1}\right)$, the maximum of CL intensity remarkably decreased from 150 to 115 by $23.3 \%$. 


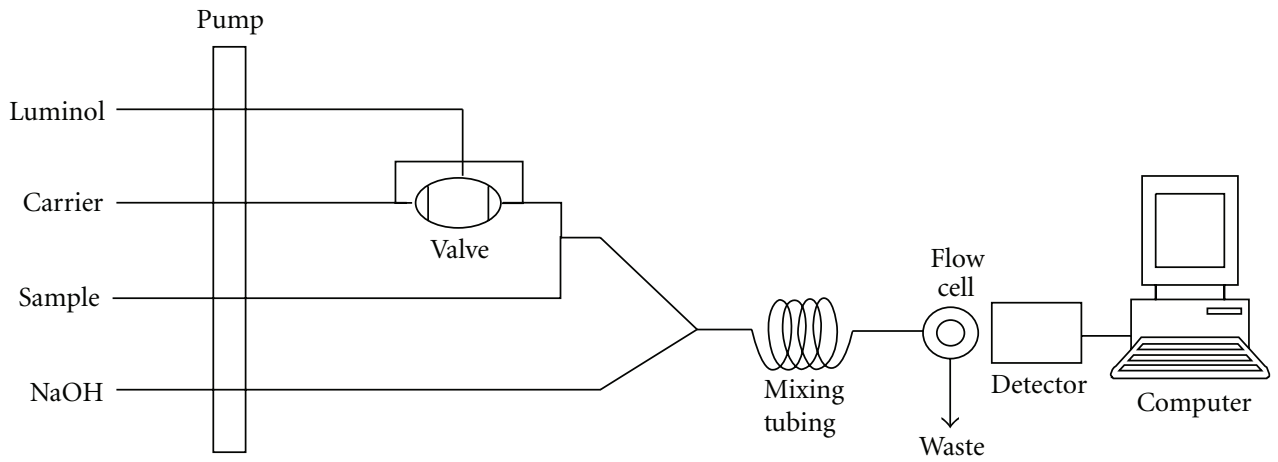

FIGURE 2: Schematic diagram of the flow-injection system for determination of ROX.

TABLE 2: Results of determination for ROX in pharmaceutical (labelled amount $75 \mathrm{mg} \mathrm{tab}^{-1}$ ).

\begin{tabular}{|c|c|c|c|c|c|}
\hline Sample no. & Added $\left(\mathrm{pg} \mathrm{mL}^{-1}\right)$ & Found $\left(\mathrm{pg} \mathrm{mL} L^{-1}\right)$ & RSD (\%) & Recovery (\%) & $\begin{array}{c}\mathrm{ROX} \\
\left(\mathrm{mg} \mathrm{tab}^{-1}\right)\end{array}$ \\
\hline \multirow{2}{*}{1} & 0 & 7.1 & 2.7 & \multirow{2}{*}{110.0} & \multirow{2}{*}{72.5} \\
\hline & 3.0 & 10.4 & 3.0 & & \\
\hline \multirow{2}{*}{2} & 0 & 7.2 & 2.4 & \multirow{2}{*}{97.1} & \multirow{2}{*}{71.0} \\
\hline & 7.0 & 14.0 & 2.5 & & \\
\hline \multirow{2}{*}{3} & 0 & 7.2 & 3.2 & \multirow{2}{*}{103.3} & \multirow{2}{*}{73.5} \\
\hline & 9.0 & 16.5 & 2.4 & & \\
\hline
\end{tabular}

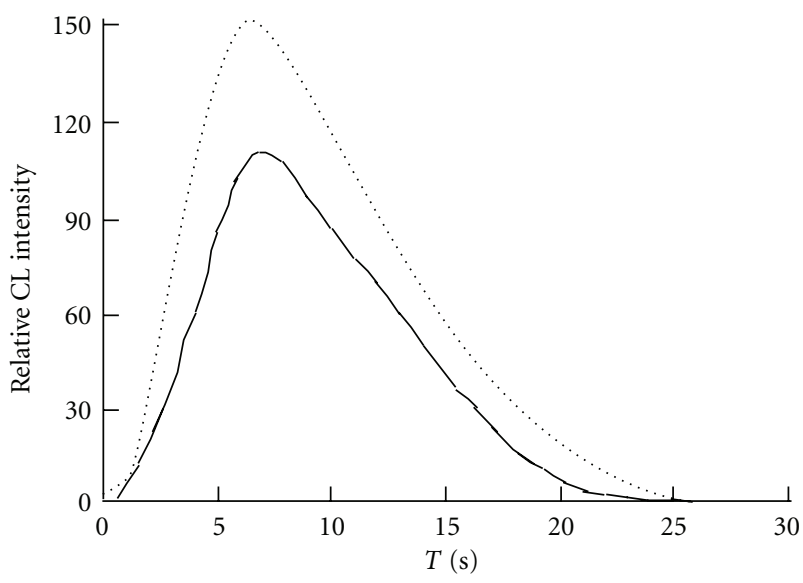

-.... Luminol-dissolved oxygen system
- Luminol-dissolved oxygen-ROX system

Luminol: $2.5 \times 10^{-5} \mathrm{~mol} \mathrm{~L}^{-1}$; $\mathrm{NaOH}: 0.025 \mathrm{~mol} \mathrm{~L}^{-1}$

ROX: 5 pg mL ${ }^{-1}$.

FIgURE 3: The CL intensity-time profile.

3.2. Effect of Luminol and Sodium Hydroxide Concentration. Owing to the nature of luminol CL reaction, which is more favorable in alkaline medium, sodium hydroxide was added to improve the sensitivity of the system. The effect of the concentration of luminol and sodium hydroxide was investigated over the ranges from $1 \times 10^{-8}$ to $1 \times 10^{-4} \mathrm{~mol} \mathrm{~L}^{-1}$ and 0.01 to $0.5 \mathrm{~mol} \mathrm{~L}^{-1}$, respectively. With increasing luminol concentration, the CL signal increased steadily until $2.5 \times$
$10^{-5} \mathrm{~mol} \mathrm{~L}^{-1}$ and then stabilised. Therefore, the concentration of $2.5 \times 10^{-5} \mathrm{~mol} \mathrm{~L}^{-1}$ luminol was chosen for the optimum condition. The result indicated the CL signal could reach a maximum value in the $\mathrm{NaOH}$ concentration of $0.025 \mathrm{~mol} \mathrm{~L}^{-1}$. Therefore, $0.025 \mathrm{~mol} \mathrm{~L}^{-1}$ sodium hydroxide was performed in all subsequent experiments.

3.3. Effect of Flow Rate and the Length of Mixing Tubing. The $\mathrm{CL}$ intensity was related to the flow rate. A lower flow rate caused broadening of the peak and slowly sampling rates. A higher flow rate could increase the signal-to-ratio $(\mathrm{S} / \mathrm{N})$ and lead to an unstable baseline. Then a flow rate of $2.0 \mathrm{~mL} \mathrm{~min}^{-1}$ was selected as an appropriate condition considering both the good precision and lower solution consumption. The effect of the length of mixing tubing on CL intensity was also tested in pursuit of producing maximum CL intensity in the flow cell. It was observed that $10.0 \mathrm{~cm}$ of mixing tubing afforded the best results with good sensitivity and reproducibility. Accordingly, $10.0 \mathrm{~cm}$ of mixing tubing was considered as an optimum length.

3.4. Performance of Proposed Method for ROX Determination. Under the optimum conditions described, the linearity of the results was examined by measuring a series of standard solutions. The decreased CL intensity was found to be proportional to ROX concentration, and the response to the concentration was linear over the range from 0.1 to $100 \mathrm{pg} \mathrm{mL}^{-1}$, and the LOD was $0.03 \mathrm{pg} \mathrm{mL}^{-1}(3 \sigma)$. The linear equation was $\Delta I_{\mathrm{CL}}=6.73 \ln C_{\mathrm{ROX}}+23.62\left(R^{2}=0.9925, n=5, \mathrm{RSDs}<\right.$ $5.0 \%)$. 
TABLE 3: Results of determination for ROX in spiked human serum.

\begin{tabular}{|c|c|c|c|c|c|}
\hline Sample no. & Added $\left(\mathrm{pg} \mathrm{mL} L^{-1}\right)$ & Found $\left(\mathrm{pg} \mathrm{mL}^{-1}\right)$ & RSD (\%) & Recovery (\%) & $\begin{array}{l}\text { ROX content }\left(\mu \mathrm{g} \mathrm{mL}^{-1}\right) \\
\text { Sample/spiked }\end{array}$ \\
\hline \multirow{2}{*}{1} & 0 & 21.3 & 2.9 & \multirow{2}{*}{96.5} & \multirow{2}{*}{$21.0 / 20.0$} \\
\hline & 20.0 & 40.6 & 5.0 & & \\
\hline \multirow{2}{*}{2} & 0 & 23.7 & 2.7 & \multirow{2}{*}{94.7} & \multirow{2}{*}{$22.9 / 24.0$} \\
\hline & 30.0 & 52.1 & 3.3 & & \\
\hline \multirow{2}{*}{3} & 0 & 29.4 & 4.9 & \multirow{2}{*}{102.0} & \multirow{2}{*}{$29.7 / 30.0$} \\
\hline & 30.0 & 60.0 & 2.3 & & \\
\hline
\end{tabular}

TABLE 4: Results of determination for ROX in spiked human urine.

\begin{tabular}{|c|c|c|c|c|c|}
\hline Sample no. & Added $\left(p g \mathrm{~mL}^{-1}\right)$ & Found $\left(\mathrm{pg} \mathrm{mL}^{-1}\right)$ & RSD (\%) & Recovery (\%) & $\begin{array}{l}\text { ROX content }\left(\mu \mathrm{g} \mathrm{mL}^{-1}\right) \\
\text { Sample/spiked }\end{array}$ \\
\hline \multirow{2}{*}{1} & 0 & 4.3 & 1.8 & \multirow{2}{*}{96.7} & \multirow{2}{*}{$4.2 / 4.5$} \\
\hline & 3.0 & 7.2 & 2.5 & & \\
\hline \multirow{2}{*}{2} & 0 & 9.8 & 2.9 & \multirow{2}{*}{90.0} & \multirow{2}{*}{$9.6 / 10.0$} \\
\hline & 3.0 & 12.5 & 2.2 & & \\
\hline \multirow{2}{*}{3} & 0 & 35.8 & 2.3 & \multirow{2}{*}{102.0} & \multirow{2}{*}{$36.0 / 36.2$} \\
\hline & 20.0 & 56.2 & 1.9 & & \\
\hline \multirow{2}{*}{4} & 0 & 20.8 & 2.1 & \multirow{2}{*}{98.0} & \multirow{2}{*}{$20.7 / 21.0$} \\
\hline & 10.0 & 30.6 & 3.0 & & \\
\hline
\end{tabular}

3.5. Interference Studies. Interference of foreign substances was tested by analyzing a standard solution of ROX to which increasing amounts of interfering species were added. Presuming interference at 5\% level, tolerable ratios of interferents with respect to $10 \mathrm{pg} \mathrm{mL}^{-1} \mathrm{ROX}$ were over 1000 times for $\mathrm{NO}_{3}^{-}, \mathrm{Ac}^{-}, \mathrm{I}^{-}, \mathrm{SO}_{4}^{2-}, \mathrm{PO}_{4}^{3-}, \mathrm{BrO}_{3}^{-}$, borate, oxalate, tartrate, urea, and uric acid; 50 times for $\mathrm{NH}_{4}^{+}, \mathrm{Mg}^{2+}, \mathrm{Ca}^{2+}, \mathrm{Ba}^{2+}$, methanol, and ethanol; 5 times for $\mathrm{Fe}^{3+}$ and $\mathrm{Fe}^{2+}$. Compounds abundant in human urine and serum such as salt, lipid and proteins caused no obvious interference for the determination of ROX.

\section{Applications}

4.1. Determination of ROX in Pharmaceutical. The determination of ROX in tablets was carried out by the procedure described in the experimental portion, and the results were summarized in Table 2, with recoveries ranging from 97.0 to $110.0 \%$ and RSDs of less than $5.0 \%$.

4.2. Determination of ROX in Spiked Human Serum and Urine. The proposed method was used in the determination of ROX in spiked human serum. In order to evaluate the validity of the proposed method, recovery studies were performed on each of the samples by adding a certain amount standard solution of ROX into $1.0 \mathrm{~mL}$ of serum sample. After homogenization, the spiked serum sample was diluted to appropriate multiples. The results were shown in Table 3 with recoveries ranging from 94.0 to $102.0 \%$.

The urine sample was collected from volunteers. The known quantities of standard solution of ROX were added into $1.0 \mathrm{~mL}$ of urine sample. After sufficient homogenization, the spiked urine sample was diluted to appropriate multiples. The determination of ROX in spiked human urine was also performed by the proposed method, and the results were shown in Table 4 with recoveries ranging from 90.0 to $102.0 \%$.

\section{Conclusions}

Based on the inhibitory effect of ROX on the luminoldissolved oxygen reaction, a simple and rapid CL method for the determination of ROX at picogram levels was first proposed. The presented method offers the advantages of low LOD, instrumental simplicity, rapidity, widely linear range, and high sensitivity. Satisfactory performance of the assay of ROX in pharmaceutical preparations and biofluids has demonstrated that the method is practical and suitable not only for the quality control analysis but also for the analysis of complex biological samples and represents an interesting alternative in pharmacological and clinical research.

\section{Acknowledgments}

The authors gratefully acknowledge the financial support from Shaanxi Province Nature Science Foundation (no. 2006B05), the NWU Graduate Innovation and Creativity Funds (nos. 09YZZ45 and 10YZZ29), and NWU Graduate Experimental Research Funds (no. 09YSY18), China.

\section{References}

[1] K. M. Drljević, V. D. Jović, U. C. Lacnjevac et al., "Voltammetric and differential pulse determination of roxithromycin," Electrochimica Acta, vol. 56, no. 1, pp. 47-52, 2010. 
[2] S. Kamogawa, K. Kagami, M. Maeda et al., "Suppressive efficacy of roxithromycin against human peripheral-blood mononuclear cells stimulated with hemolytic streptococci superantigen," European Journal of Pharmacology, vol. 602, no. 2-3, pp. 439-447, 2009.

[3] C. Kousoulos, G. Tsatsou, Y. Dotsikas, C. Apostolou, and Y. L. Loukas, "Validation of a fully automated high throughput liquid chromatographic/tandem mass spectrometric method for roxithromycin quantification in human plasma. Application to a bioequivalence study," Biomedical Chromatography, vol. 22, no. 5, pp. 494-501, 2008.

[4] N. Ogawa, Y. Sugawara, Y. Fujiwara, and T. Noma, "Roxithromycin promotes lymphocyte apoptosis in Dermatophagoidessensitive asthma patients," European Journal of Pharmacology, vol. 474, no. 2-3, pp. 273-281, 2003.

[5] S. T. H. Sherazi, M. Ali, and S. A. Mahesar, "Application of Fourier-transform infrared (FT-IR) transmission spectroscopy for the estimation of roxithromycin in pharmaceutical formulations," Vibrational Spectroscopy, vol. 55, no. 1, pp. 115-118, 2011.

[6] F. K. Główka and M. Karaźniewicz-Łada, "Determination of roxithromycin in human plasma by HPLC with fluorescence and UV absorbance detection: application to a pharmacokinetic study," Journal of Chromatography B, vol. 852, no. 1-2, pp. 669-673, 2007.

[7] P. Wang, M. Qi, and X. Jin, "Determination of roxithromycin in rat lung tissue by liquid chromatography-mass spectrometry," Journal of Pharmaceutical and Biomedical Analysis, vol. 39, no. 3-4, pp. 618-623, 2005.

[8] J. Olšovská, Z. Kameník, and T. Cajthaml, "Hyphenated ultra high-performance liquid chromatography-Nano Quantity Analyte Detector technique for determination of compounds with low UV absorption," Journal of Chromatography A, vol. 1216, no. 30, pp. 5774-5778, 2009.

[9] H. Wan, F. Zhao, W. Wu, and B. Zeng, "Direct electron transfer and voltammetric determination of roxithromycin at a singlewall carbon nanotube coated glassy carbon electrode," Colloids and Surfaces B, vol. 82, no. 2, pp. 427-431, 2011.

[10] J. Peng and X. Hu, "A simple fluorescence quenching method for roxithromycin determination using CdTe quantum dots as probes," Journal of Luminescence, vol. 131, no. 5, pp. 952-955, 2011.

[11] C. X. Li, J. Han, Y. Wang, Y. S. Yan, X. H. Xu, and J. M. Pan, "Extraction and mechanism investigation of trace roxithromycin in real water samples by use of ionic liquid-salt aqueous two-phase system," Analytica Chimica Acta, vol. 653, no. 2, pp. 178-183, 2009.

[12] J. Wang, Z. Yang, X. Wang, and N. Yang, "Capillary electrophoresis with gold nanoparticles enhanced electrochemiluminescence for the detection of roxithromycin," Talanta, vol. 76, no. 1, pp. 85-90, 2008.

[13] Z. Song, Y. Liu, and X. Xie, "In Vitro monitoring picogram roxithromycin in human urine using flow injection chemiluminescence procedure," Current Drug Metabolism, vol. 7, no. 4, pp. 389-395, 2006.

[14] A. Roda, M. Guardigli, E. Michelini, M. Mirasoli, and P. Pasini, "Analytical bioluminescence and chemiluminescence," Analytical Chemistry, vol. 75, no. 21, pp. 462A-470A, 2003.

[15] Z. Song and L. Wang, "Chemiluminescence investigation of detection of rutin in medicine and human urine using controlled-reagent-release technology," Journal of Agricultural and Food Chemistry, vol. 49, no. 12, pp. 5697-5701, 2001.
[16] Y. Liu, Z. Song, F. Dong, and L. Zhang, "Flow injection chemiluminescence determination of sudan I in hot chilli sauce," Journal of Agricultural and Food Chemistry, vol. 55, no. 3, pp. 614-617, 2007.

[17] Z. Wang, D. Chen, X. Gao, and S. Zhenghua, "Subpicogram determination of melamine in milk products using a luminolmyoglobin chemiluminescence system," Journal of Agricultural and Food Chemistry, vol. 57, no. 9, pp. 3464-3469, 2009.

[18] Z. Song and S. Hou, "Sub-picogram determination of Vitamin B12 in pharmaceuticals and human serum using flow injection with chemiluminescence detection," Analytica Chimica Acta, vol. 488, no. 1, pp. 71-79, 2003.

[19] L. Niu, Z. Song, and D. Chen, "Determination of Sudan IV in hot chilli powder with luminol/dissolved oxygen chemiluminescence system," Journal of the Science of Food and Agriculture, vol. 90, no. 2, pp. 338-342, 2010.

[20] X. Xie, X. He, X. Qiu, and Z. Song, "In vitro monitoring chlorogenic acid in human urine and serum by a flow injection system exploiting the luminol-dissolved oxygen chemiluminescence reaction," Current Drug Metabolism, vol. 8, no. 8, pp. 773-777, 2007. 


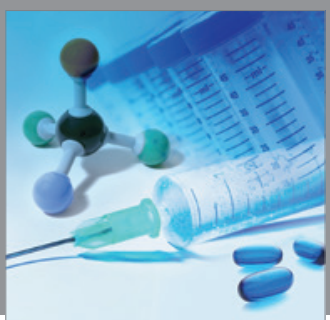

International Journal of

Medicinal Chemistry

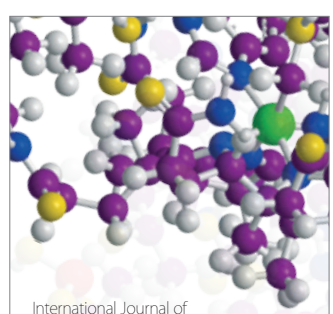

Carbohydrate Chemistry

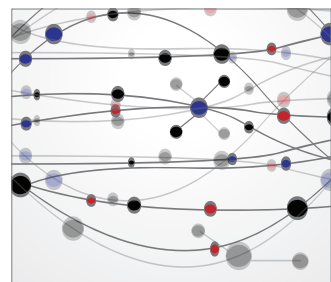

The Scientific World Journal
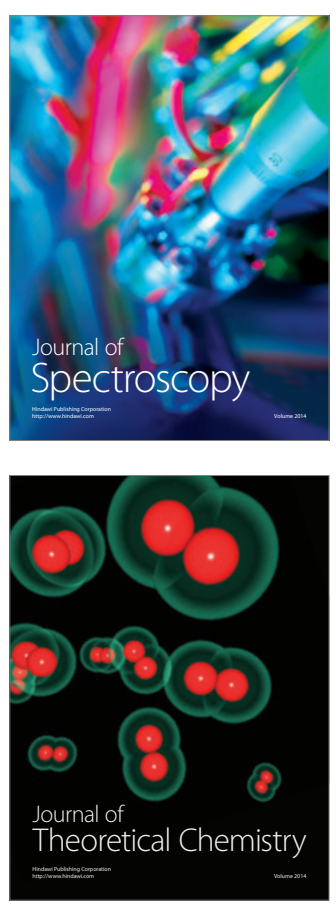
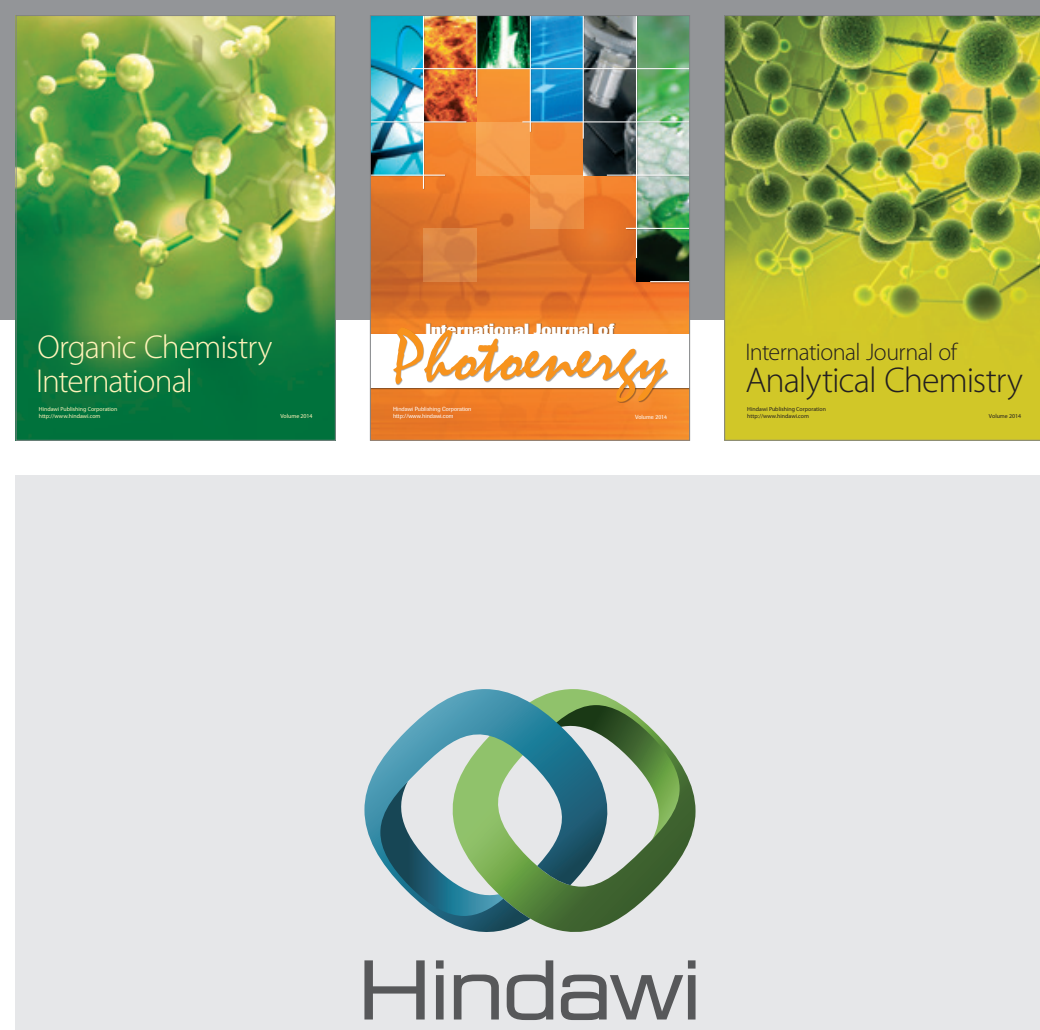

Submit your manuscripts at

http://www.hindawi.com
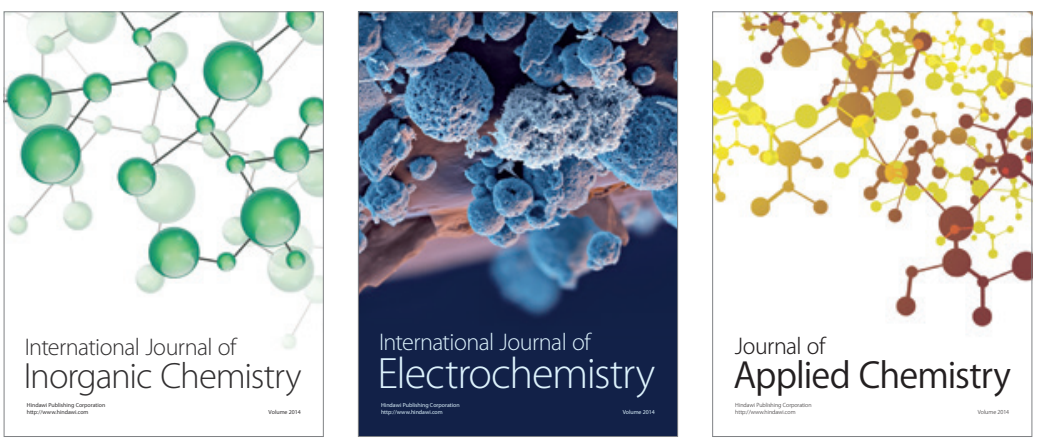

Journal of

Applied Chemistry
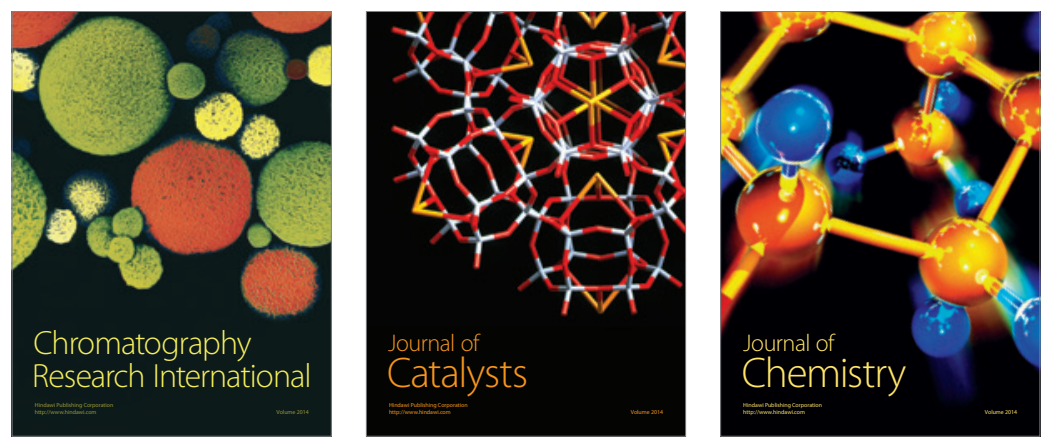
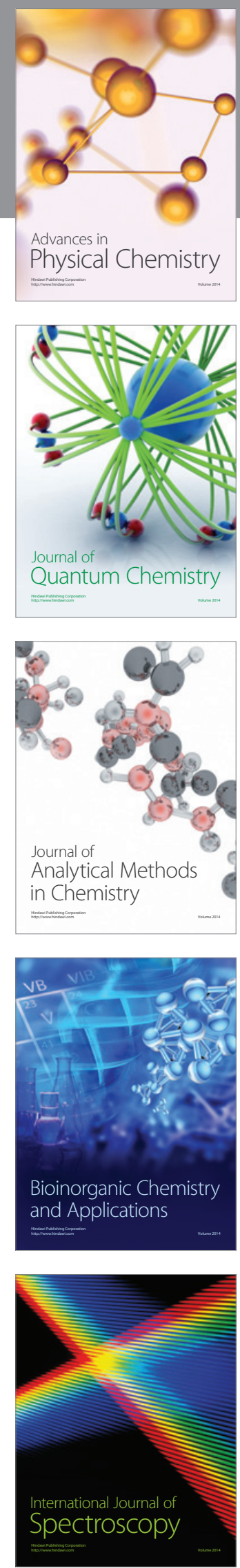